\title{
Histomorphological spectrum of ovarian tumors - A tertiary care center experience
}

\author{
Sampurna K, Jyothi B \\ Assistant Professor, Department of Pathology, Osmania Medical College/Hospital, Hyderabad, Telangana, India
}

Background: Ovarian tumors are a heterogeneous group of neoplasms with variable clinical, morphological, and histological features. Ovarian cancer is the leading cause of death in females. Aims and Objectives: (1) To study and characterize the ovarian tumors based on gross and histopathological features. (2) To study prevalence and age distribution of various ovarian tumors. (3) To study the clinical features in patients with ovarian tumors. (4)To compare the frequency of benign and malignant neoplasms of the ovary with other studies. Materials and Methods: This is a prospective study conducted in Upgraded Department of Pathology, Modern Government maternity hospital, and Osmania General Hospital, Hyderabad, Telangana from March 2018 to February 2021. A total of 200 ovarian tumors were studied. Results: Out of 200 ovarian tumors, 132 were benign, seven were borderline and 61 were malignant. The surface epithelial tumors were the most common tumors accounting for 159 cases $(79.5 \%)$, germ cell tumors were seen in 27 cases $(13.5 \%)$, sex-cord stromal tumors formed 10 cases $(5 \%)$, and metastasis in 4 cases $(2 \%)$. Conclusion: Ovary is a common site of tumors in the female genital tract and usually presents with a variety of clinocomorphological and histological features. Benign are the most common, of these surface epithelial tumors are the commonest, affects mainly reproductive age group.

Key words: Germ cell tumors; Histopathology; Ovarian tumors; Surface epithelial tumors

\section{Access this article online}

Website:

http://nepjol.info/index.php/AJMS DOI: 10.3126/ajms.v13i1.39783

E-ISSN: 2091-0576

P-ISSN: $2467-9100$

Copyright (c) 2022 Asian Journal of Medical Sciences

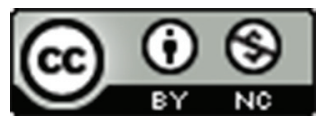

This work is licensed under a Creative Commons Attribution-NonCommercial 4.0 International License.

\section{INTRODUCTION}

Ovarian cancers account for $25 \%$ of the all gynaecological malignancies and $3^{\text {rd }}$ most common cause of death due to malignancies of female genital tract in the western world. ${ }^{1}$ In India, ovarian tumors account for $80 \%$ of all the gynecological malignancies. ${ }^{2}$ The ovary, after the uterus and cervix, is the second common site for the development of gynecological malignancy and prognosis remains poor. ${ }^{3}$ The ovarian tumors are not a single entity but a complex-wide spectrum of neoplasms involving a variety of histologic tissues ranging from epithelial tissues, connective tissues, specialized hormone secreting cells to germinal or embryonal cells. ${ }^{4}$ Generally ovarian tumors occur in perimenopausal and post-menopausal women, infrequently in children also. The risk of developing an ovarian malignancy peaks in fifth decade of life. Risk factors for ovarian cancer are much less clear than for other genital tumors, but nulliparity, family history, and heritable mutation play a role in the tumor development. ${ }^{5,6}$ Women between 40 and 59 years of age who have taken oral contraceptives or undergone tubal ligation have a reduced risk of developing a cancer. ${ }^{7,8}$

\section{Aims and objectives}

To study-clinical presentation, gross and histological characters, and characterize the ovarian tumors based on gross and histopathological features, prevalence, distribution of benign and malignant ovarian neoplasms.

\section{MATERIALS AND METHODS}

This is a prospective study conducted in the Upgraded Department of Pathology, Modern Government maternity hospital and Osmania General Hospital, Hyderabad, Telangana from march 2018 to February 2021. 
A total of 200 ovarian tumors were studied. Of these 200 ovarian tumors, 132 were benign, 7 were borderline and 61 were malignant. The gross specimen received were fixed in $10 \%$ formalin for $24 \mathrm{~h}$ and from every specimen, multiple sections were taken from the representative site for histological examination. The number of blocks varied from four to eight in number. Sections were processed in paraffin, which was cut at five microns thickness. Sections were stained with conventional hematoxylin and eosin stain. The lesions were classified and studied as per the WHO classification of ovarian tumors. As the study is focused on histological characterization of ovarian tumors, Immunohistochemistry was not done in this study.

\section{RESULTS}

A total of 200 ovarian tumors were studied. Of these 200 ovarian tumors, 132 were benign, 7 were borderline and 61 were malignant and majority of these tumors seen in parous women (Table 1). Majority of patients (26.5\%)presented with pain abdomen and back ache, while $17 \%$ presented with mass abdomen, $5 \%$ of cases had post menopausal bleeding. Other presentations included amenorrhoea, urinary symptoms, loss of weight and ascites (Table 2). There was a wide size range in ovarian neoplasms in the present study. It ranged from $3 \times 2 \mathrm{~cm}$ to $30 \times 20 \mathrm{~cm}$. Majority of them $89(44.5 \%)$ were in the size range of $6-10 \mathrm{~cm}$, followed by $54(27 \%)$ in the size range of $11-19 \mathrm{~cm}$. The age range of the tumors diagnosed varied from 13 to 73 years, with a peak incidence in $3^{\text {rd }}$ and $4^{\text {th }}$ decade of life. Maximum benign cases were seen between 41-50 years. Maximum number of malignant tumors were seen between 51-60 years. Youngest patient was 12 years old, oldest was 76 years old. The maximum number of tumors were seen in the $4^{\text {th }}$ decade (Table 3 ).

In the present study, $\mathrm{TAH}$ with $\mathrm{BSO}$ was the most common procedure opted in 106 cases (50.3\%) followed by unilateral oophorectomy in 78 cases (39\%), bilateral oophorectomy in 16 cases (8\%). Right sided tumors of ovary $94(47 \%)$ were more common than the left sided tumors 82 (41\%). 24 $(12 \%)$ cases were bilateral out of them 15 were malignant, one borderline and 9 were benign (Table 4).
The majority of tumors(nearly $60 \%$ ) were cystic and only $8 \%$ were solid and rest were solid and cystic. and majority of cystic neoplasms were benign (Table 5).

The tumors were classified according to WHO histologic classification of ovarian tumors and the incidence of different histologic types noted. The surface epithelial tumors were the commonest tumors accounting for 159 cases $(79.5 \%)$, germ cell tumors were seen in 27 cases $(13.5 \%)$, sex-cord stromal tumors formed 10 cases $(5 \%)$ and metastasis in 4 cases $(2 \%)$ (Table 6$)$.

\section{Surface epithelial tumors}

The commonest epithelial tumors were serous 87 cases (43.5\%), 60 mucinous (30\%), 5 Brenner (2.5\%), and 2 Endometroid tumor (1\%) remaining poorly differentiated carcinomas (Table 7).

Three cases of benign Brenner tumor were seen. The largest was seen in a 38 year old female patient and measured 20x15 cm. Grossly, the tumors were solid with smooth, slightly bosselated external surface. The largest tumor showed cystic areas. All of them were unilateral (Figure 1). Microscopically, the nucleus was grooved in some of the cells, giving a coffee bean appearance. Poorly differentiated carcinoma on cut section showed solid consistency and areas of necrosis (Figure 2).

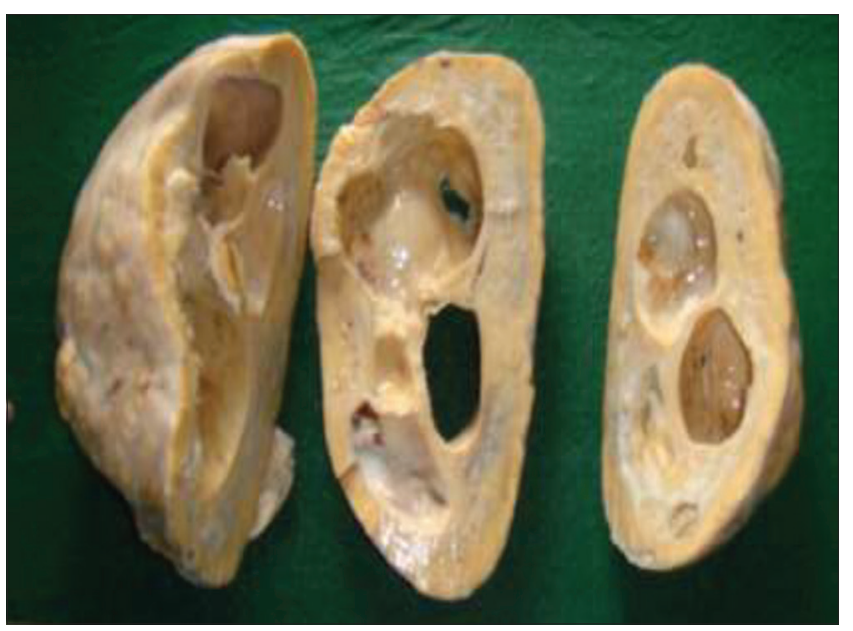

Figure 1: Brenner tumor

\begin{tabular}{|c|c|c|c|c|c|c|}
\hline Age & Benign & Percentage & Borderline & Percentage & Malignant & Percentage \\
\hline Upto 20 & 4 & 2 & 0 & 0 & 1 & 0.5 \\
\hline $21-30$ & 14 & 7 & 1 & 0.5 & 7 & 3.5 \\
\hline $31-40$ & 29 & 14.5 & 0 & 0 & 13 & 6.5 \\
\hline $41-50$ & 36 & 18 & 1 & 0.5 & 13 & 6.5 \\
\hline $51-60$ & 32 & 16.5 & 3 & 1.5 & 17 & 8 \\
\hline $61-70$ & 15 & 7.5 & 2 & 1 & 8 & 4 \\
\hline $71-80$ & 2 & 1 & 0 & 0 & 2 & 1 \\
\hline Total & 132 & 66 & 7 & 3.5 & 61 & 30.5 \\
\hline
\end{tabular}


Two cases of endometroid adenocarcinoma were seen. One is in a 45 year old nulliparous women measuring $11 \times 9 \mathrm{~cm}$, the cut section of which was solid and cystic. Microscopically, the tumor showed areas of necrosis and haemorrhage (Figure 3).

\section{Serous tumors}

Serous tumors formed the majority of ovarian neoplasms in the study. There were a total of 87 serous tumors, constituting about $43.5 \%$ (Table 8 ).

All serous tumours $>1 \mathrm{cms}$ were considered as serous cystadenomas. The serous cystadenoma was the most commonest accounting for 59 cases $(29.5 \%)$ of all ovarian neoplasms.

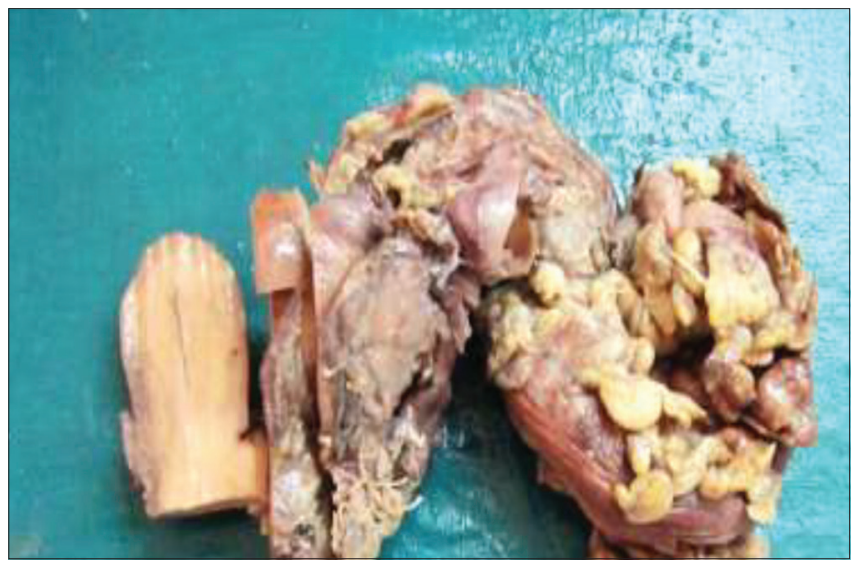

Figure 2: Poorly differentiated carcinoma

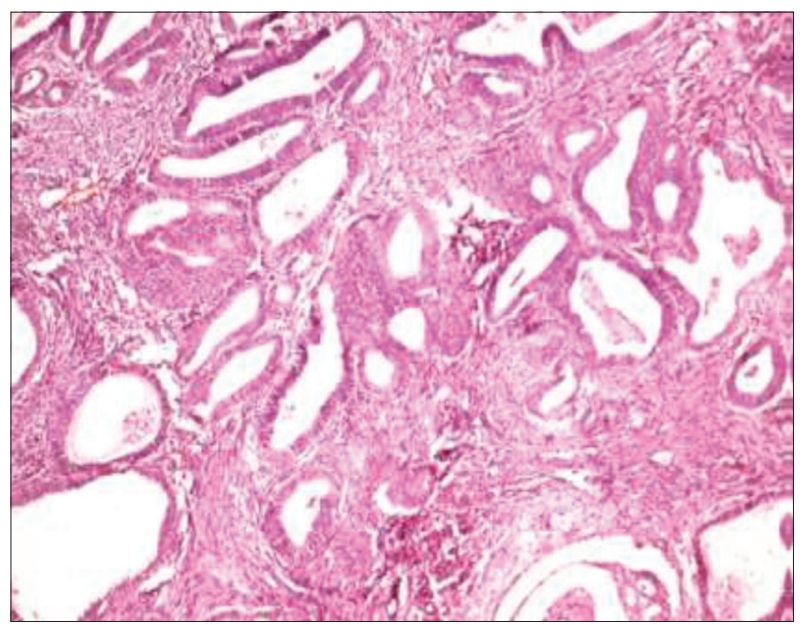

Figure 3: H \& E (×10) - Endometroid carcinoma
The size of the largest benign serous cystadenoma was $20 \times 16 \mathrm{~cm}$ and the smallest was $3 \times 3 \mathrm{~cm}$ with smooth shiny external surface. Majority of the tumours exuded clear fluid with one case of seromucinous fluid and 3 cases showed features of torsion with prominent dilated veins over the surface. Bilaterality was seen in 2 cases. The largest malignant tumor $10 \times 8 \mathrm{~cm}$ in size and its cut section was partly solid and partly cystic (Figure 4). Serous cystadenocarcinoma cases on microscopy were predominantly solid and cystic and showed stratification and nuclear pleomorphism and high mitosis (Figure 5).

\section{Mucinous tumors}

These constituted the second most common ovarian neoplasms and included 60 cases (30\%) of all ovarian tumors (Table 9).

Grossly, the largest tumor measured 30x20 cm, which was also the largest tumor encountered in the present study. The benign tumors were cystic while borderline and

$\begin{aligned} & \text { Table 2: The distribution of tumors in parous } \\
& \text { women }\end{aligned}$
\begin{tabular}{lccc} 
Types of tumors & Unmarried & \multicolumn{2}{c}{ Married } \\
\cline { 2 - 4 } & & Nulliparous & Parous \\
\hline Benign & 4 & 16 & 113 \\
Borderline & - & - & 7 \\
Malignant & 2 & 8 & 50 \\
\hline
\end{tabular}

\begin{tabular}{lccc}
\multicolumn{4}{l}{ Table 3: Clinical presentation of patients } \\
\hline Clinical presentation & Benign & Borderline & Malignant \\
\hline Mass per abdomen & 34 & 3 & 27 \\
Associated pain abdomen & 47 & 3 & 20 \\
Dysfunctional uterine & 5 & - & - \\
bleeding & & & \\
Amenorrhea & 4 & - & 2 \\
Postmenopausal bleeding & 10 & 1 & 9 \\
Urinary symptoms & 7 & - & - \\
Loss of weight & 4 & - & 1 \\
Ascites & 2 & - & 8 \\
\hline
\end{tabular}

\begin{tabular}{lcc} 
Table 4: Laterality of specimens & \\
\hline Side of ovary involved & Number of cases & Percentage \\
\hline Right & 94 & 47 \\
Left & 82 & 41 \\
Bilateral & 24 & 12 \\
\hline
\end{tabular}

\section{Table 5: Consistency of benign, borderline, and malignant tumors in the present study}

\begin{tabular}{lccccc}
\hline Consistency & Benign & Borderline & Malignant & Total & Percentage \\
\hline Cystic & 98 & 5 & 16 & 119 & 59.5 \\
Solid and cystic & 29 & 2 & 34 & 65 & 32.5 \\
Solid & 5 & - & 11 & 16 & 8 \\
Total & 132 & 7 & 61 & 200 & 100 \\
\hline
\end{tabular}




\begin{tabular}{lcc} 
Table 6: Number of cases and percentage \\
distribution of various types of ovarian tumors \\
\hline Types of tumor & Number of cases & Percentage \\
\hline Surface epithelial tumors & 159 & 79.5 \\
Sex-cord stromal tumors & 10 & 5 \\
Germ cell tumors & 27 & 13.5 \\
Others (metastasis) & 4 & 2 \\
Total & 200 & 100 \\
\hline
\end{tabular}

\begin{tabular}{lcc}
\multicolumn{3}{l}{ Table 7: Distribution of surface epithelial tumors } \\
\hline Types of surface epithelial tumors & $\begin{array}{c}\text { Number } \\
\text { of cases }\end{array}$ & Percentage \\
\hline Serous cystadenoma & 59 & 29.5 \\
Serous cysadenofibroma & 04 & 2 \\
Borderline serous tumor & 02 & 1 \\
Serous cystadenocarcinoma & 22 & 11 \\
Mucinous cysadenoma & 43 & 21.5 \\
Borderline mucinous tumor & 05 & 2.5 \\
Mucinous cysadenocarcinoma & 12 & 6 \\
Brenner tumor & 05 & 2.5 \\
Endometroid tumor & 02 & 1 \\
Poorly differentiated carcinoma & 05 & 2.5 \\
Total & 200 & 100 \\
\hline
\end{tabular}

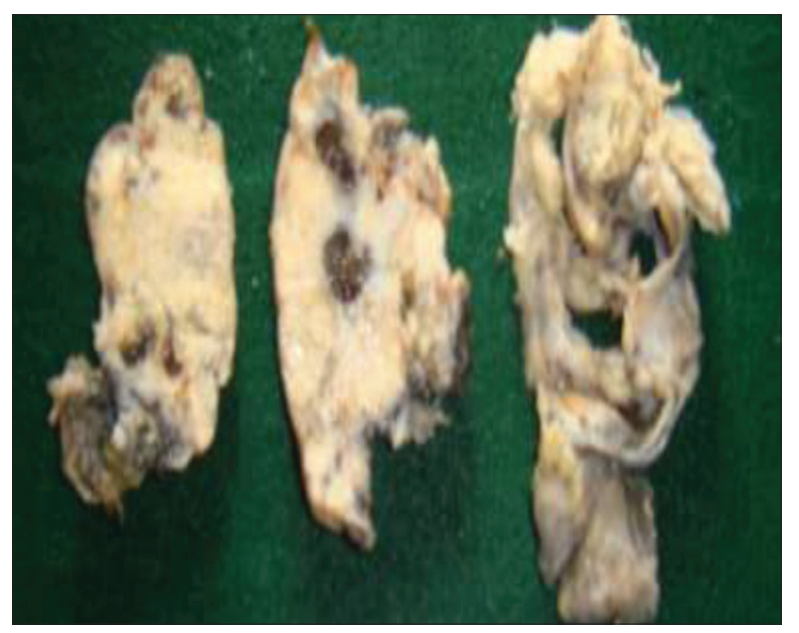

Figure 4: Serous cystadenocarcinoma

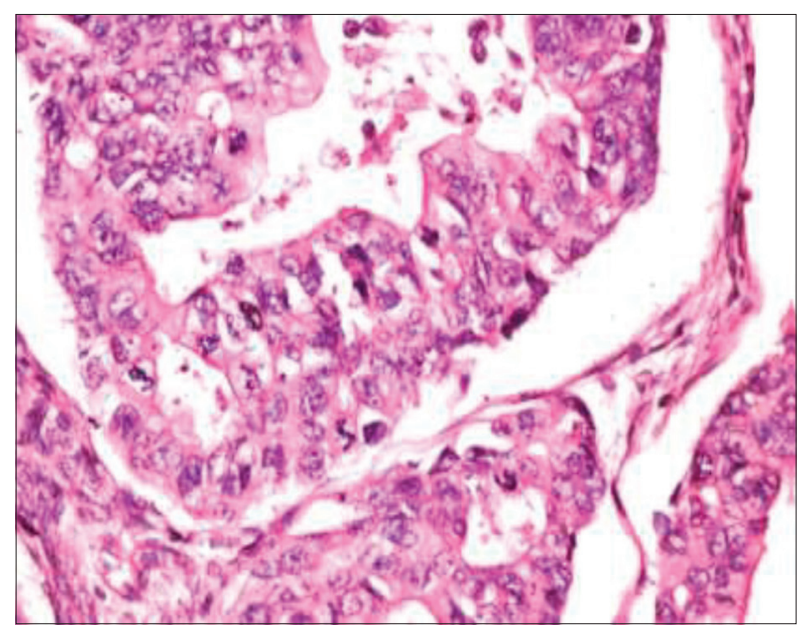

Figure 5: H \& E $(\times 40)$ - Serous cystadenocarcinoma malignant ones were partly solid and partly cystic containing mucinous fluid. Forty three(43) of all mucinous tumors were benign mucinous cystadenomas compromising highest percentage in this category (21\%) with microscopy showing a lining of tall columnar epithelium with apical mucin (Figure 6). Five cases of borderline mucinous were diagnosed in tumor with papillary projections lined by atypical cells up to one- two cell thickness and no stromal invasion was seen. Malignant tumours showed complex papillary pattern with pleomorphic mucious cells. Areas of necrosis and stromal invasion were seen.

\section{Germ cell tumors}

Germ cell tumors constituted about 27 cases $(13.5 \%)$ of all ovarian tumors (Table 10). Dysgerminomas constituted $2.5 \%$ of cases which on cutsection grossly showed yellow white ,soft,fleshy areas (Figure 7) and microscopy showed sheets and cords of cells separated by thin fibrous septae which is infiltrates with mature lymphocytes (Figure 8). Endodermal sinus tumors constituted only $0.5 \%$ (01 case) of cases in this study and grossly showed solid and cystic areas (Figure 9).

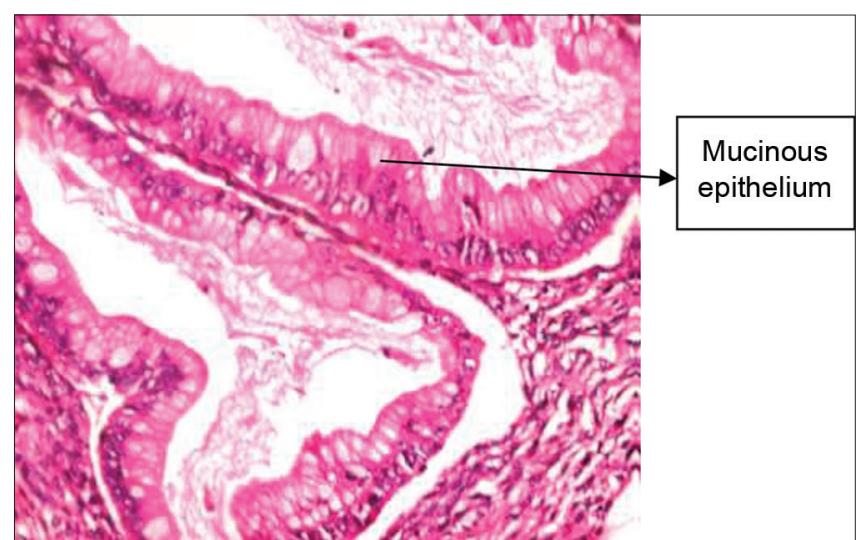

Figure 6: H \& E (×40) - Mucinous cystadenoma

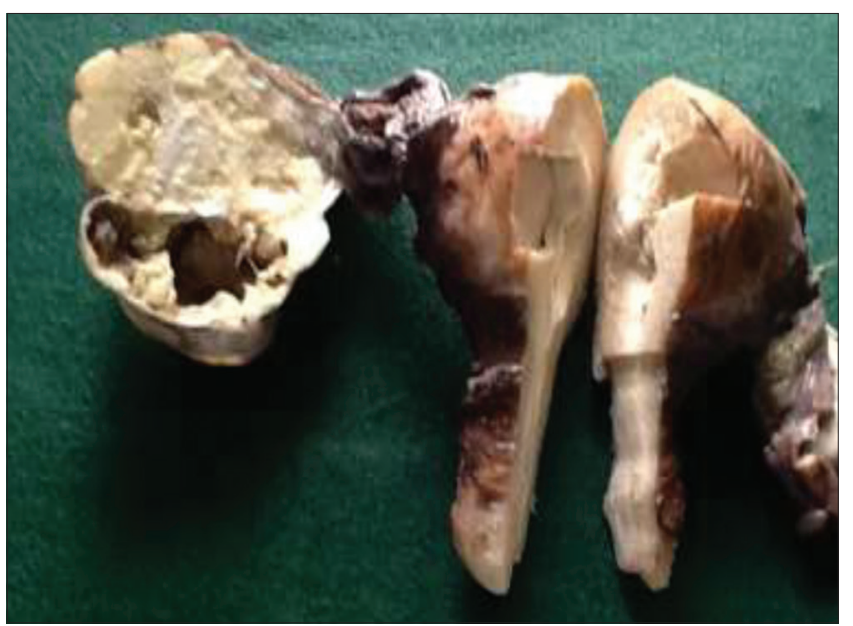

Figure 7: Dysgerminoma

Asian Journal of Medical Sciences | Jan $2022 \mid$ Vol $13 \mid$ Issue 1 


\begin{tabular}{lcc} 
Table 8: Distribution of serous tumors & \\
\hline Type & Number of cases & Percentage \\
\hline Serous cysadenoma & 59 & 34.5 \\
Borderline serous tumor & 02 & 01 \\
Serous cysadenocarcinoma & 22 & 11 \\
Serous cysadenofibroma & 04 & 2 \\
Total & 87 & 43.5 \\
\hline
\end{tabular}

\begin{tabular}{lcc} 
Table 9: Distribution of mucinous tumors \\
\hline Tumor type & $\begin{array}{c}\text { Number of } \\
\text { cases }\end{array}$ & Percentage \\
\hline Mucinous cysadenoma & 43 & 21.5 \\
Borderline mucinous tumor & 05 & 2.5 \\
Mucinous cysadenocarcinoma & 12 & 6 \\
Total & 60 & $30 \%$ \\
\hline
\end{tabular}

\begin{tabular}{lcc}
\multicolumn{3}{l}{ Table 10: Distribution of germ cell tumors } \\
\hline Tumor type & Number of cases & Percentage \\
\hline Teratoma & 21 & 10.5 \\
Dysgerminoma & 05 & 2.5 \\
Endodermal sinus tumor & 01 & 0.5 \\
Total & 27 & 13.5 \\
\hline
\end{tabular}

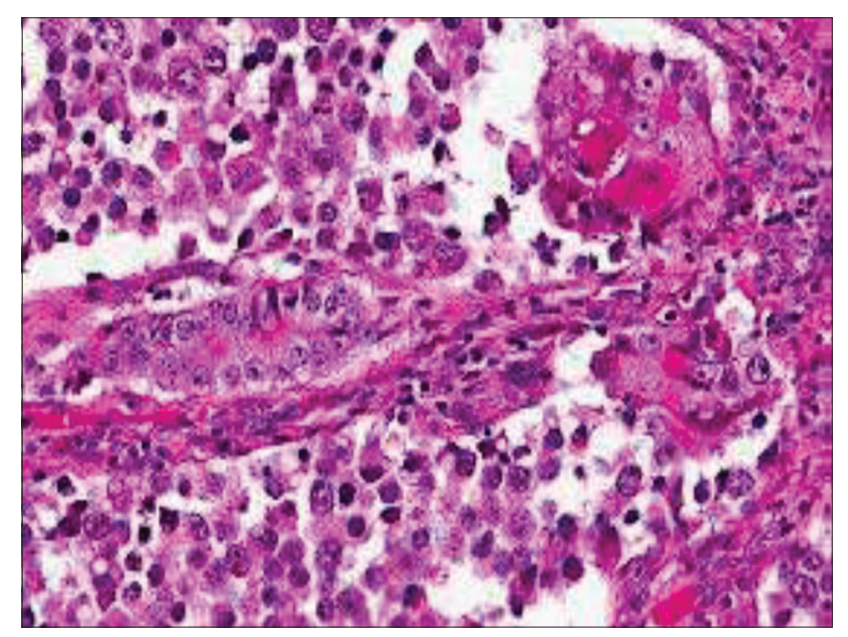

Figure 8: H \& E (×10) - Dysgerminoma

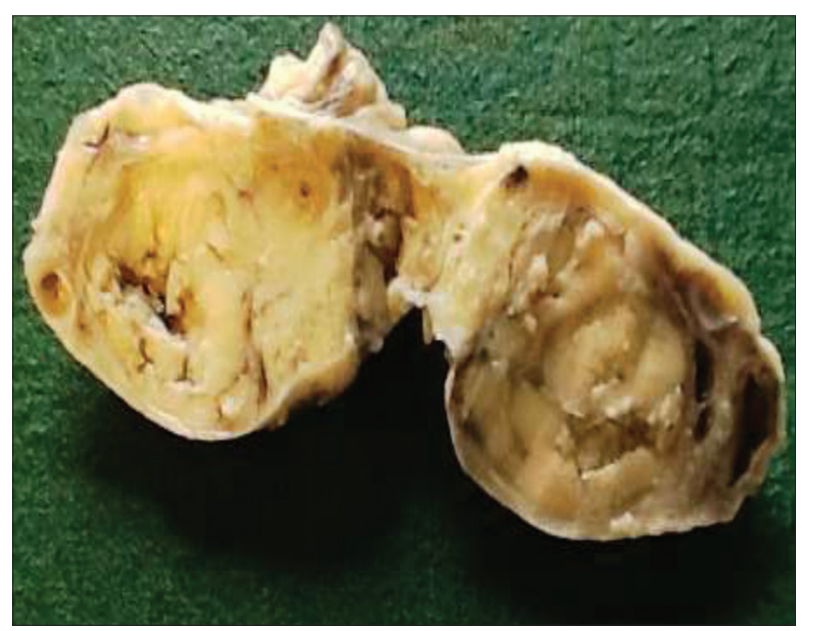

Figure 9: Endodermal sinus tumor
Sex cord stromal tumors

Few cases of sex cord stromal tumors were also studied in this study. The granolosa cell tumor grossly on cut section showed pale yellow colour and microscopy showed cuboidal to polygonal cells in anastomosing cords and sheets along with Call-Exner bodies (Figures 10 and 11).

\section{DISCUSSION}

Ovarian neoplasms are one of the most fascinating tumors in women in terms of their histogenesis, clinical behavior, and malignant potentiality. They account for a disproportionate number of fatal cancers, being responsible for almost half of the deaths from cancers of the female genital tract.

Histomorphological evaluation of ovarian tumors forms an integral part of the evaluation of these neoplasms.

In the present study, peak incidence of ovarian tumors is seen in the age group of 51 to 60 . This is in contrast to the studies like that done by Verma and Bhatia ${ }^{9}$ and Jha and $\mathrm{Karki}^{10}$ which the majority of patients were in the 31 to 40 age group.

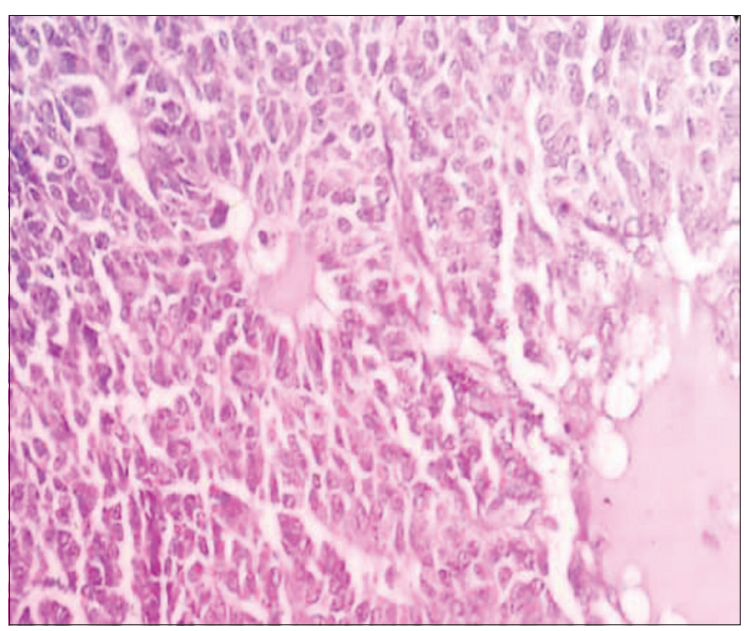

Figure 10: H \& E (×10) - Granulosa cell tumor

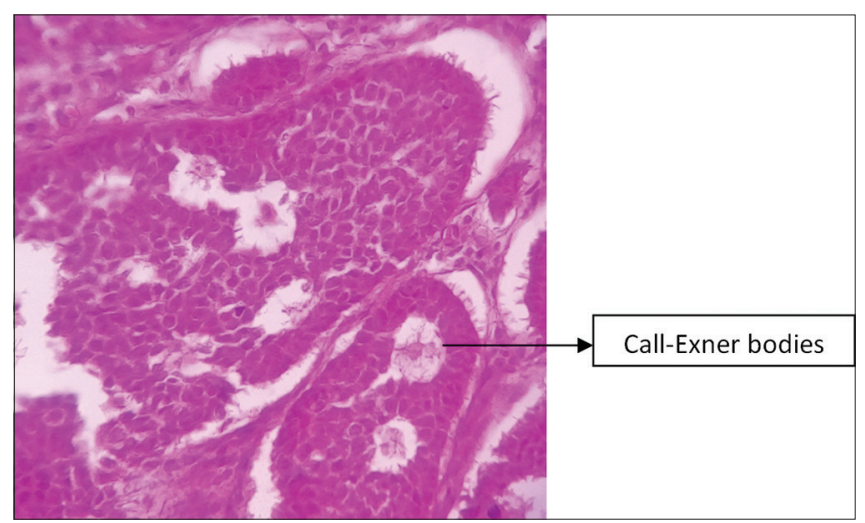

Figure 11: H\&E (×40) - Granulosa cell tumor 
This study results had shown that $66 \%$ of patients were benign. This compares well with earlier studies like the one published by Verma and Bhatia9 (66.99\%), but they observed slightly lower cases than other recent studies like Swamy et al11 who had $71 \%$ benign tumors in their series. $30.5 \%$ of tumors in this study are malignant. This was comparable to studies like Verma et al9 but is much more than Jha et al 10(16\%) and Swamy et al (25\%).

The percentage of borderline tumors in this study was $3.5 \%$ which was comparable to the study done by Gupta et al12 (4.1\%).

Most of the benign tumors in this study were unilateral with only $12 \%$ cases showing bilateral tumor involvement. This is comparable to findings of study done by Jha et al 10 (93.34\% unilateral). In contrast Swamy et al11 reported a bilaterality rate of $29 \%$ in benign tumors. In malignant tumors that were noted a bilaterality rate of just $7.5 \%$ compared to Swamy et al11 who reported a bilaterality rate of $50 \%$ and Jha et al10 in which $42 \%$ of the malignant tumors were bilateral.

Serous cystadenoma comprised 59 cases $(29.5 \%)$ in this study while Ganga Pilli et al 13reported $31.2 \%$ and Tyagi et al 14 reported $39.5 \%$.

Sex cord stromal tumors formed $10(5 \%)$ of cases. This finding was similar to a study done by Gupta et al 12 which reported $7.06 \%$ of sex cord stromal tumor.

The germ cell tumors accounted for 27 cases (13.01\%). This was similar to the study done by Jagadeeshwari et al $2(13.2 \%)$ and slightly lower than that reported by Tyagi et al $14(23.58 \%)$ Commonest amongst the germ cell tumor was teratoma (21 cases- $10.5 \%)$.

There were 4 cases of metastatic tumours which accounted for 2.\%. Three were from GIT primaries metastasizing to ovary and one from SCC. Gupta et al 12 reported 6.28\% while Ganga Pilli et al 13 reported $0.7 \%$ of metastatic tumors.

\section{Limitations of the study}

Follow-up of patients was done as it was difficult to trace the cases which came to this hospital from different states with no continuous follow-up and incomplete addresses.

\section{CONCLUSION}

Ovarian tumors are one of the most researched topics in gynecological pathology.

Benign are the most common, of these surface epithelial tumors are the commonest, affects mainly reproductive age group. Clinical features are vague and are late manifestations.
Malignant tumors are less common, serous are more prone to going into malignancy. Thus categorizing the ovarian tumors according to histopathological features (WHO) into various types helps to know the clinical presentation, treatment, clinical outcome, and prognosis of the tumors.

\section{ACKNOWLEDGMENT}

We thank the patients without whom the study would not be possible and we also thank all the technicians whop helped in processing the tissues.

\section{REFERENCES}

1. Novak ER, Jones GS and Jones HW. Ovarian tumors. In: Gynaecological and Obstetrical Pathology. $6^{\text {th }}$ ed. Philadelphia, PA: Saunders; 1967. p. 365-413.

2. Jagadeshwari N, Satyabhama RR and Rao KS. Incidence of ovarian tumours. J Obset Gynecol India. 1971;21:747-752.

3. Rosai JR. Ackerman's Surgical Pathology. $10^{\text {th }}$ ed., Vol. 2. New Delhi: Elsevier Publication; 2012. p. 1553-1609.

4. Howkins $\mathrm{J}$ and Bourne G. Shaw's Textbook of Gynaecology. $13^{\text {th }}$ ed., Vol. 2. Elsevier Publication; 2006. p. 41-47.

5. Azizs S, Kuperstein G, Rosem B, Cole D, Nedelew R, Mclaughlin J, et al. A genetic epidemiologic study of carcinoma of the fallopian tube. Gynecol Oncol. 2001;80(3):341-345. http://doi.org/10.1006/gyno.2000.6095

6. Narod SA and Boyd J. Current understanding of the epidemiology, and clinical implication of BRCA 1 and BRCA 2 for ovarian cancer. Curr Opin Obstet Gynecol 2002;14(1):19-26. http://doi.org/10.1097/00001703-200202000-00004

7. Narod SA, Sun P, Ghadirian P, Lynch H, Isaacs C, Garber J, Weber $B$, et al. Tubal ligation and risk of ovarian cancer in carriers of BRCA1 and BRCA2 mutations: A case-control study. Lancet. 2001;357(9267):1467-1470.

http://doi.org/10.1016/s0140-6736(00)04642-0

8. Ness RB, Grisso JA, Vergona R, Klapper J, Morgan M, Wheeler JE, et al. Oral contraceptives, other methods of contraception, and risk of ovarian cancer. Epidemiology 2001;12(3):307-312. http://doi.org/10.1097/00001648-200105000-00010

9. Verma A and Bhatia A. Ovarian neoplasms a study of 403 tumors. J Obstet Gynecol India. 1981;31:106-111.

10. Jha R and Karki S. Histological pattern of ovarian tumors and their age distribution. Nepal Med Coll J. 2008;10(2):81-85.

11. Swamy GG and Satyanarayana N. Clinicopathological analysis of ovarian tumors a study on five years samples. Nepal Med Coll J. 2010;12(4):221-223.

12. Gupta SC, Singh PA, Mehrotra TN and Agarwal R. A Clinicopathological study of ovarian tumours. Ind. J Pathol Microbiol. 1986;29(4):354-362.

13. Pilli G, Suneeta KP, Dhaded AV and Yenni VV. Ovarian tumors study of 282 cases. J Indian Med Assoc. 2002;100(7):420, 423-4, 447.

14. Tyagi SP, Tyagi GK and Logani K. A pathological study of 120 ovarian tumors. J Obst Gynecol India. 1967;17:423-433. 
Authors Contribution:

JB- Concept and design of the study, prepared first draft of manuscript, Interpreted the results; reviewed the literature and manuscript preparation; SK- Concept, coordination, statistical analysis and interpretation, preparation of manuscript and revision of the manuscript.

Work attributed to:

Osmania Medical College, Hyderabad - 500 001, Telangana, India.

Orcid ID:

Dr. Jyothi B- (10 https://orcid.org/0000-0002-9086-339X

Dr. Sampurna K- (D) https://orcid.org/0000-0003-3578-4872 